UJBM, Vol. 4, No. 1, January - June 2005, pp 32-39

ISSN 0975-3311 | https://doi.org/10.12725/ujbm.5.5

\title{
PROCESS EFFICIENCY IN WELLNESS SECTOR
}

\section{T.V. Raju* and Satya S.**}

The 'Wellness Sector' is an emerging sector in India. This concept is catching up the world over as this sector focuses on the maintenance of health rather than cure. The trauma involved in cure, high escalating costs and the shrinking size of families makes Wellness a better option than cure.

India is known amongst westerners for its ancient wisdom and knowledge. If we plan well, this sector can become another IT sector in terms of generating goodwill and tourist interest in our country. To enable this the industry should streamline service provision and make the process of delivery international in standards. To enable this, the industry must offer comprehensive services. Service provision must be well thought our and streamlined. Process efficiency, apart from providing good standards of customer encounters, should also aim at making the customer a life long member.

\section{Process Efficiency in Wellness Sector}

\section{Wellness Sector Defined:}

Wellness is a new trend and buzz word. There is an attempt to streamline this area and focus on its business opportunifies around the world. Wellness, as an industry, can be mapped only if the definition of the terminology is sound and clear. "A commonly accepted definition is important for

- Wellness is a widely used term amongst health and fitness professionals and the general public.

*Director, R.V. Institute of Management, Bangalore

** MS Ramaiah Institute of Technology, Bangalore 
- The term is defined by many different people in many different ways.

- The lack of a common definition causes confusion;

- The lack of a clear definition makes it impossible to build a sound body of scientific knowledge related to wellness.

- The lack of sound knowledge can lead to quackery and mis-information concerning wellness." 1

"Wellness is first and foremost a choice to assume responsibility for the quality of your life. It begins with a conscious decision to shape a healthy lifestyle. Wellness is a mind set, a predisposition to adopt a series of key principles in varied life areas that lead to high levels of well-being and life satisfaction". (Dona Dell, Living Well Center).

The Merriam-Webster online dictionary defines wellness as: "The quality or state of being in good health especially as an actively sought goal."

The National Wellness Institute definition is as follows:

"Welness is an active process of becoming aware of and making choices towards a more successful existence".

The key words in this first sentence are process, aware, choice and success.

- Process means that we never arrive at a point where there is no possibility of improving.

- Aware means that we are by our nature continuously seeking more information about how we can improve.

- Choices mean that we have considered a variety of options and select those that seem to be in our best interest.

- Success is determined by each individual to be their personal collection of accomplishments for their life.

Wellness is multidimensional. A popular model adopted by many universities, corporates and public health programs encompasses 6 dimensions:

Social

Occupational

Spiritual

Physical

1. "The Research Digest" Serial 3 No. 15, Dec 2001, Presidents Council on Physical fitness and sports. 
Intellectual

Emotional

"Wellness is a choice - a decision you make towards optimal health. Wellness is a way of life - a lifestyle you design to achieve your highest potential for well-being. Wellness is a process - a developing awareness that there is no end point, but that health and happiness are possible in each moment, here and now. Wellness is a positive acceptance of oneself. Wellness is the interaction of the body, mind and spirit - the appreciation that everything we do, think, feel, and believe has an impact on our state of health." Travis

Bouchard et al (1990) "Wellness is a multi dimensional state of being describing the existence of positive health in an individual as exemplified as quality of life and sense of well being"

Schafer (1996) defined wellness as the "process of living at one's highest possible level as a whole person and promoting the same for others a continuing challenge, rather than something attained and then forgotten."

Dunn (1977) defined wellness as "an integrated method of functioning which is oriented toward maximizing the potential of which the individual is capable. It requires that the individual maintain a continuum of balance and purposeful direction with the environment in which he is functioning."

\section{Wellness Centers' Services and Delivery Process}

From the definitions of wellness it is clear that wellness is a wide concept and can be applied to any aspect of life namely Spiritual, Social, Occupational, Physical, Intellectual and Emotional. On studying some of the wellness service providers in Bangalore it was clear that the scope of service provision was pertaining to one or two aspects, namely spiritual and physical and no package addresses all the aspects. Though there are claims that these services will have a rub off effect on general well being the fact remains that no service is aimed or packaged to serve the entire scope of the term wellness. So, for the purpose of this study, the service provides who aimed at physical wellness packages were focused upon.

In the production process the R \& D designs the end product and the rejection or acceptance of the finished product is based on the pre set standards of the laboratory. In service, the end product is just an experience by the client.

2. Services Marketing, Valarie A. Zeithaml \& Mary Jo Bitner, 3rd Edition, Tata Mc Graw Hill 
'The foundation or the building blocks for satisfactory services are through the service encounters, which is also termed as the moment of truth'2. In such a situation how the industry plans its delivery is the first aspect this study will learn. How the existing process can be streamlined better is the application aspect that the study will aim to suggest. Process in the service sector is nothing but an 'Encounter cascade $^{3}$ which delivers certain pre planned services to the clients. This flow of events for each department is streamlined and a delivery map is portrayed as a picture, which is the service system. This facilitates the understanding different people involved in the provision and helps them deal with the system objectively.

A simple observation study in five Wellness Centers revealed specific areas where. improvements can be implemented. By looking at service processes from a purely operational perspective, they can be categorized into four broad groups. ${ }^{4}$ The Wellness sector will be classified under the first and third category (in Figure 1,1) since the services offered in these sectors are intangible and the outcomes are directed at peoples' minds. At the same time there are tangible elements as the services are directed at the peoples' bodies. Messages, magnetic and water therapies are done to soothe the body and mind. Receiving Wellness Services requires an investment of time from people. The recipients will have to be physically present at the service providing point. They need to involve themselves and learn the science underlying the service provision to understand its full benefits. Their experience is the direct outcome of their understanding and belief in the fundamental principle, which underlines the services.

Fig 1.1: Understanding the Nature of the Service Act

\begin{tabular}{|l|l|l|}
\hline \begin{tabular}{|l|} 
What is the nature of the \\
Service Act?
\end{tabular} & \multicolumn{1}{|c|}{ Pho or what is the Direct Recipient of the Service } \\
\hline Tangible Actions & \begin{tabular}{|l|l|}
\hline \multicolumn{1}{|c|}{ People Processing } \\
(Services directed at \\
People's bodies): \\
Passenger transportation \\
Health Care \\
Lodging \\
Beauty Salons \\
Physical Therapy \\
Fitness Center \\
Restaurant/Bars \\
Barbers \\
Funeral Services
\end{tabular} \\
$\begin{array}{l}\text { (Services directed at } \\
\text { Physical possessions): } \\
\text { Freight Transportation } \\
\text { Repair and Maintenance } \\
\text { Warehousing/Storage } \\
\text { Office Cleaning Services } \\
\text { Retail Distribution } \\
\text { Laundry and dry cleaning } \\
\text { Refueling } \\
\text { Landscaping/Gardening } \\
\text { Disposal/Recycling }\end{array}$ \\
\hline
\end{tabular}

3. Services Marketing Integrating customer focus across the firm. Valarie V. Zeithaml et al.

4. Services Marketing People, Technology, Strategy. Christopher Lovelock $4^{\text {th }}$ Edition, Pearson Education 


\begin{tabular}{|c|c|c|}
\hline Intangible Actions & $\begin{array}{l}\text { Mental Stimulus } \\
\text { Processing } \\
\text { (Services directed al } \\
\text { people's minds): } \\
\text { Advertising/PR } \\
\text { Arts and entertainment } \\
\text { Broadcasting/Cable } \\
\text { Management Consulting } \\
\text { Education } \\
\text { Information Services } \\
\text { Music Concerts } \\
\text { Psychotherapy } \\
\text { Religion } \\
\text { Voice telephone }\end{array}$ & $\begin{array}{l}\text { Information Processing } \\
\text { (Services directed at } \\
\text { intangible assets): } \\
\text { Accounting } \\
\text { Banking } \\
\text { Data Processing } \\
\text { Data Transmission } \\
\text { Insurance } \\
\text { Legal Services } \\
\text { Programming } \\
\text { Research } \\
\text { Securities Investment } \\
\text { Software Consulting }\end{array}$ \\
\hline
\end{tabular}

Source: Services Marketing People, Technology, Strategy Christopher Lovelock, $4^{\text {th }}$ ed, Pearson Publication, p. 38.

The procedure, as observed, had the following cascading flow of events.

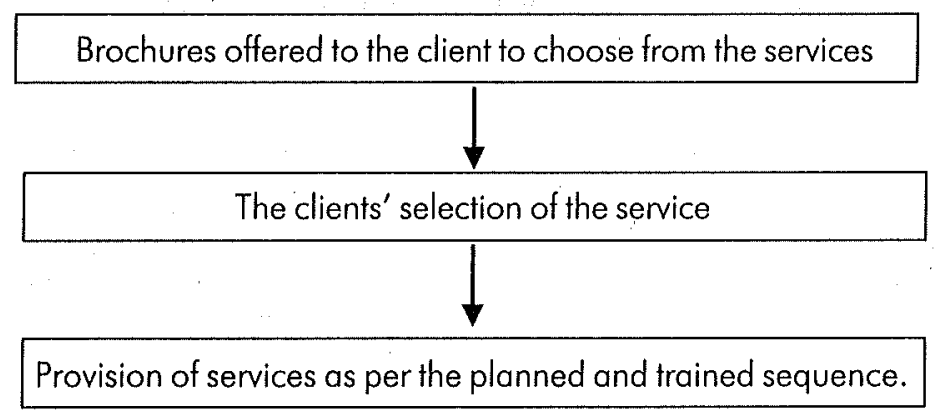

\section{Scientific Selection of Wellness Treatment based on Customers' Needs}

The clients were offered a brochure where various services were mentioned in names derived out of their Sanskrit origin; for example Puzhithal. In two centers even this basic instrument was not available for the clients to choose their services 
from. This makes the delivery rather unscientific, as the clients have no idea as to what they are buying. Though there are English explanations of this particular treatment in two lines there is no real clue as to the scientific benefits the services can offer.

Secondly, unlike a beauty treatment or hairstyle preference, wellness services can offer deeper benefits than just superficial cosmetic benefits. From this perspective, the providers should assess the client and suggest to him the appropriate offer based on his life style, age, etc. and get the treatment to focus. In the field of medicine the client partakes in making the doctors aware of his ailments but the treatment takes place based on the expertise of the doctor. In some cases where the situation is not an emergency the doctor might explain the treatment procedures to the client and he would choose one alternate mode of treatment based on the availability of finance, time, etc. Primarily, there is a vast difference between beauty parlor services and physical wellness services and medical treatment for cure. By letting the client choose the treatment he wants to have, the whole offer becomes more cosmetic than scientific. This is because the client has no knowledge of the treatment and cannot decide which is the best for him.

It will be a good idea in the first place to understand the customer's physical condition and his goals for wellness and then design a package to suit his 'requirements. 'Understanding consumers' service expectations is the key to the delivery of quality senvice'. ${ }^{5}$ After all each client would require a different program. A senior citizen will focus on the prevention of certain susceptible ailments, which he is prone to, namely avoiding arthritis or asthma attacks. A young executive who is or the fast track of career growth will aim at reducing his stress and avoiding blood pressure problems. So, based on the physical conditions, expectations and wellness goals of the client the service provider can offer a program specially tailored for each patient's requirement. The service provider has more expertise in the subject than the client. But to offer a good package knowing the expectations of the client is very important and this aspect is completely absent in the present process. A well thought out questionnaire can be planned and executed before the service offer, so that the customer's expectations and wellness goals can be evaluated. Then a specialist can review this information, and from the actual physical conditions of the client, a common goal can be set for the wellness package. This will give a meaningful purpose to the whole program and make it more fruitful than a beauty treatment service.

5. "Service Intangibility and its impact on consumer expectations of service quality" Journal of Services Marketing Vol 14, 2002, pp 9-26. MCB University Press. 


\section{Service Offer - An Analysis}

The service offer can be split into further finer points: the materials used for the treatments the person offering the treatment and the outcomes. In all the Wellness centers where observation was conducted the client had no clue as to what was happening. Be it a magnetic treatment or a specific kind of oil massage, the customers were more or less treated as dolls. They did not know anything about the treatment. It is very essential to explain to clients, before the treatment, the underlying principles on which the treatment is based. The ingredients that go into the making of the oil, the procedure followed by the service provider and the outcomes that can be expected should be clearly explained to the client. This way he gets confidence and would adopt the system on a long term basis. After all Wellness is a conscious adaptation to follow certain key principles in life to improve the quality of life in a continuous process. To enable customers to follow these principles and make them inculcate these into their mainstream life, service providers should have a more holistic approach to their entire business. They should look at customers as their life long members and give them key advise pertaining to food, exercise, and elaborate as to how to get the best leverage out of these wellness programs.

If this aspect is built into the service provision then long-term customer relations' management should be built into the system so that the service providers can keep in touch with the clients on a regular basis and take them to the next stage of wellness. At present customers are served with no long term plans in the agenda. This way an excellent chance to offer him lifetime services is lost. This is another area where the process can be streamlined and strengthened. So, the cascading events and the blue print suggested is illustrated below.

\section{Customer Defined Service Standards}

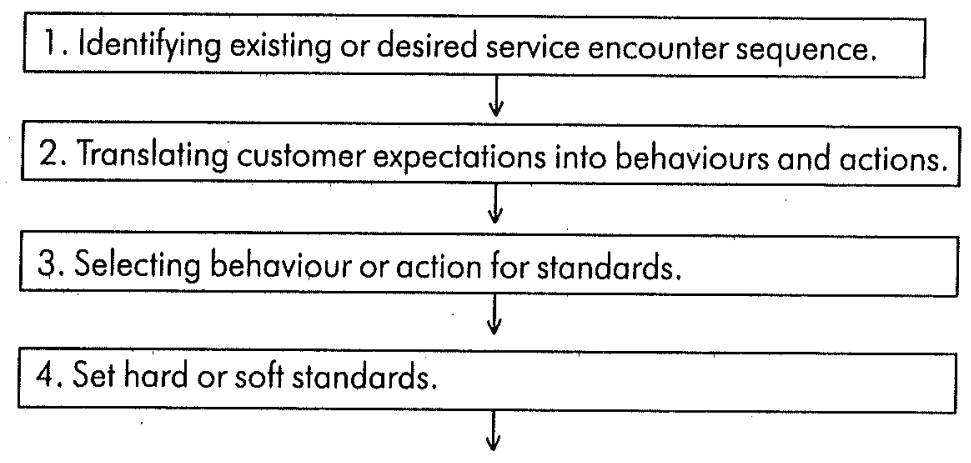




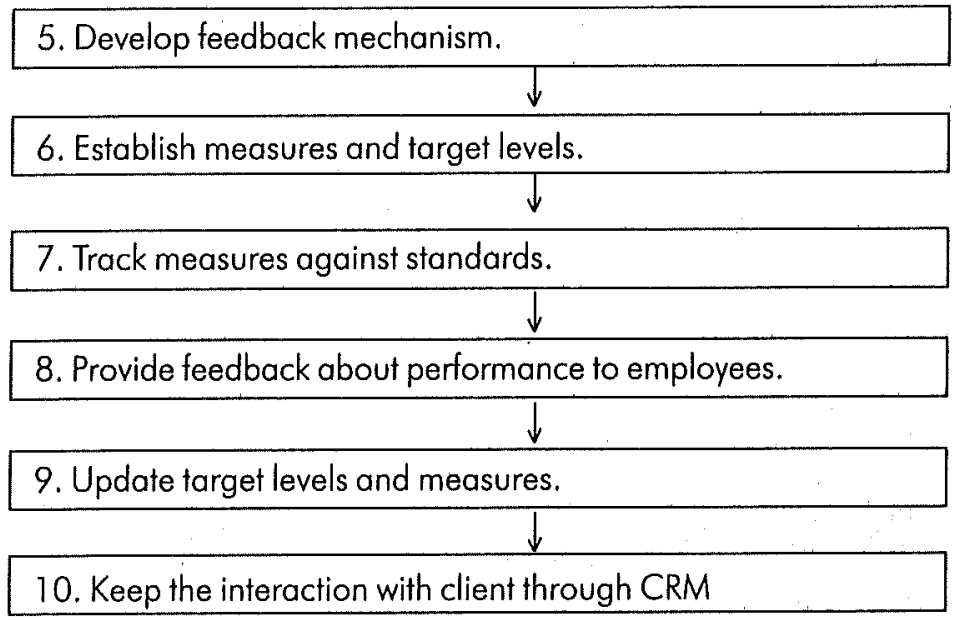

\section{Conclusion}

These processes for setting customer defined standards are comprehensive and can be guidelines to set systems in place. This process can be adopted and based on this, a service blue print can be prepared. Even the selection and training of personnel can be planned based on the outcome planned. Feedback mechanisms can be built in and 'Hard and Soft Standards's for measurement can be set. Hard measurements consist of counts or audits or timely actions that provide feedback about the operational performance of a service standard. Hard standards can be continuously and operationally measured without asking for the customers' opinion. Once this is done, the tracking of measures back to set standards gets easier. Soft standards can be measured by implementing a comprehensive CRM package. Apart from just feedback the CRM will also aim at providing constant updates to consumers and retain them for life.

6. Services Marketing Integrating customer focus across the firm. Valarie V. Zeithaml ef al. 